\title{
Effect of High Dose Spironolactone and Chlorthalidone in Essential Hypertension: Relation to Plasma Renin Activity and Plasma Volume
}

\author{
Stephen N. Hunyor*, Andrew J. Zweiflert, Lennart Hansson,+ M. Anthony Schork ${ }^{* *}$ and Charles Ellis $+\dagger$
}

From: Hypertension Research, Department of Internal Medicine, University of Michigan. Ann Arbor, USA

Summary: The effect on blood pressure of high (400 mg/day-S400) and moderate dose $(200 \mathrm{mg} /$ day-S200) spironolactone and chlorthalidone $(100 \mathrm{mg} / \mathrm{day}$ $-\mathrm{C} 100)$, given in a random double-blind manner was related to plasma renin activity and plasma volume in 38 essential hypertensives.

The fall in pressure from a control of $154 / 103 \mathrm{~mm} \mathrm{Hg}$ was essentially the same after four weeks of each drug $\mathrm{S} 400 \triangle B P 24 / 13 \mathrm{~mm}, \mathrm{~S} 20018 / 9 \mathrm{~mm}$, C100 $17 / 12 \mathrm{~mm}$ (all $P<0.001$ ).

Twelve of 37 patients (32\%) had low initial renin, but this appeared as responsive to the chlorthalidone stimulus as that of the normal renin group. The antihypertensive effect of all regimens was unrelated to plasma renin activity.

Plasma volume was significantly lowered at the end of each treatment period, but the decline could not be correlated with blood pressure effects. Patients with initially low plasma volume were more likely to respond to $\$ 400$ $(r=0.545, P<0.01)$, whereas the antihypertensive effect of the $\mathrm{S} 200$ and C100 regimens was independent of this variable.

\footnotetext{
"Recipient of a Travel Grant of the Nationa! Heart Foundation of Australia

Present address: Staff Specialist Physician, R.G. Hospital, Concord

†Professor of Internal Medicine

†Present address: Department of Medicine V. Sahlgrenska

Sjukhuset, Göteborg, Sweden

* Professor of Biostatistics

†+Cardiovascular Trainee

Supported in part by a USPHS Grant (No. 2-P11-GM 15559)

to the Upjohn Centre for Clinical Pharmacology. University Hospital, Ann Arbor

Correspondence: Dr. Stephen H. Hunyor, Renal/Metabolic Unit,

R.G.H. Concord,

Hospital Road, Concord, N.S.W. 2139

Accepted for publication: 9 August, 1974
}

Low renin essential hypertension (LRH) and its response to spironolactone has been the subject of several recent studies ${ }^{1-4}$. Should the response in the low renin sub-group prove to be as marked as some of these reports suggest, then $20-30 \%$ of the essential hypertensive population may be expected to maintain good blood pressure control on S100-S200 mg/day. Identification of this sub-group with renin estimation under strictly controlled conditions would become part of the routine hypertensive screen.

Excess of an unidentified mineralocorticoid in low renin hypertension was first postulated following observations on the effect of aminoglutethimide by Woods et $a l^{5}$, and further support has come from spironolactone studies $^{13}{ }^{3}$. Adlin and colleagues ${ }^{4}$, Jose et al. ${ }^{6}$ and Vaughan et al. ${ }^{7}$ have not found a selective spironolactone action and alternate explanations have been sought for low renin hypertension. Thus an overexpanded plasma volume, inappropriately high aldosterone secretion rate $^{8}$ and impaired adrenergic sensitivity ${ }^{9}$ have all been investigated, while increased aldosterone sensitivity ${ }^{6}$ has also been postulated.

Recently it was found that the "low" renin sub-group may also be unduly responsive to the antihypertensive action of hydrochlorothiazide 4 . In contrast, in four patients with primary aldosteronism ${ }^{10}$, a favourable blood pressure response was obtained to $\mathrm{S} 200$ but not to hydrochlorothiazide.

Vaughan et al. ${ }^{7}$ find a similar blood pressure effect from spironolactone and chlorthalidone, in either low or normal renin groups, in a study involving use of open label preparations and predominantly $200 \mathrm{mg}$ or less spironolactone.

Previous studies showing a lack of selective action in low renin hypertension ${ }^{4,6}$ of "high dose" spironolactone employed $200 \mathrm{mg} /$ day for 12 and 4 weeks respectively. The term "low normal" plasma renin activity has been intro- 
duced by one group 4 to demonstrate a selective action of S200. This selective effect became apparent only when the "low normal" and the truly "low" renin groups were collectively compared with the blood pressure response of the "normal" renin group.

The antihypertensive effect of chlorthalidone was similar to that of moderate and high dose spironolactone in the double blind study of 38 uncomplicated essential hypertensives reported here. In this communication the antihypertensive effect of these regimens on the low and normal renin sub-groups is analysed and examined in the light of changes in plasma volume and weight.

\section{Patients and Methods}

Thirty-eight essential hypertensives (resting recumbent diastolic pressure $>90 \mathrm{~mm} \mathrm{Hg}$ ) agreed to participate in this study. Ages ranged from 20 to 59 years and none had greater than grade II hypertensive retinopathy. Secondary causes of hypertension were ruled out by thorough clinical examination and laboratory examination.

Schedule of Tablets, Visits and Tests

Three drug regimens, spironolactone $300-400 \mathrm{mg} /$ day, spironolactone $200 \mathrm{mg} /$ day and chlorthalidone $100 \mathrm{mg} / \mathrm{day}$ were each given for four weeks. Spironolactone was given as $100 \mathrm{mg}$ and chlorthalidone as $50 \mathrm{mg}$ tablets. The high dose spironolactone consisted of two weeks $300 \mathrm{mg} / \mathrm{day}$ followed by a further two weeks of $400 \mathrm{mg} /$ day. All antihypertensive medications and tranqullizers were discontinued at least four weeks and oral contraceptives six months prior to the first visit. Placebo periods of at least two weeks preceded each drug.

Clinic visits and serum electrolyte estimations were spaced at two weekly intervals. Placebo tablets were given as 2,3 , and 4 tablets per day to correspond with the active drug schedules. Random tablet counts on at least one occasion in each patient showed better than $95 \%$ adherence.

\section{Randomization and Double-blind Procedure}

Drug and placebo administration were randomized using a classical $6 \times 6$ Latin square method. The patients and the clinic nurse taking blood pressure were unaware of the tablet schedules or timing of plasma volume determinations.

\section{Blood Pressure Measurement}

Office blood pressures were taken at the same time of day, in the lying position after 15 minutes rest. The average was obtained of three readings over five minutes. Phase $\mathrm{V}$ Korotkoff sounds was taken as the diastolic end point and mean BP was derived as diastolic plus $1 / 3$ pulse pressure. Individual drug effects were assessed using the immediate preceding placebo BP as control. Randomization of the study population resulted in placebo blood pressure before each drug treatment being similar for the group as a whole.

\section{Plasma Volume}

Plasma volume was measured after the initial placebo period and at the end of each four weeks drug treatment.
The estimation was performed in the morning, fasting, after thirty minutes recumbency. Evans' blue dye, exactly $5 \mathrm{ml}$ of a $0.5 \%$ solution, was injected and flushed with $5-10 \mathrm{ml}$ normal saline. Optical density in samples taken 10,15 and 20 minutes later from the other arm, without venous congestion, was extrapolated to zero time. Previous results from this laboratory ${ }^{11}$ show that this estimation is reproducible within close limits over a period of several weeks. Plasma volume has been expressed both as $\mathrm{ml} / \mathrm{cm}$ height and as $\mathrm{ml} / \mathrm{kg}$ weight.

\section{Plasma Renin Activity}

Plasma renin activity was measured according to the method of Haber et al. ${ }^{12}$ by Radioimmunoassay of the angiotensin I generated after plasma incubation. The initial $\left(\mathrm{PRA}^{1}\right)$ sample was drawn after two weeks on placebo, with salt restriction (100 meq sodium/day) during the second week, and after strict two hour ambulation. The sample was immediately placed in ice and centrifuged within fifteen minutes in a refrigerated centrifuge $\left(4^{\circ} \mathrm{C}\right)$. The plasma was then frozen and kept in this state until analysis. In 20 patients a further PRA sample (PRA ${ }^{2}$ ) was drawn under similar conditions, but after the patient had taken chlorthalidone $100 \mathrm{mg} /$ day for four weeks. Plasma renin activity was expressed as $\mathbf{n g} \%$ /hour and the ratio $\mathrm{PRA}^{2} / \mathrm{PRA}^{1}$ served as an expression of the rise in renin with diuretic therapy.

Estimations were performed in duplicate with the error of duplicate estimations being $4.5 \%$ (range $0-12 \%$ ). Recovery rate of a known amount of angiotensin I was $116 \%$. In this laboratory, with the preparation described, a level for PRA ${ }^{1}$ of less than $50 \mathrm{ng} \%$ /hour falls more than $2 \mathrm{SD}$ below the mean of a group of normals similarly prepared. Thus, patients below this level are considered as having low renin essential hypertension.

\section{Urinary Aldosterone}

Urinary aldosterone excretion was measured by a double isotope dilution method* in a twenty-four hour sample collected on the last day of the initial placebo period. Completeness of urine collection was checked by relating urinary creatinine to body mass.

\section{Statistical Methods}

T-test for paired T-test statistics, student's T-test for comparison of two groups and correlations were performed using the CONSTAT computer program of the Statistical Research Laboratory at the University of Michigan.

\section{Results}

The ages of patients ranged from 20 to 59 years (mean 43) and the sex distribution was 27 males, 11 females. Twenty-six patients were white, ten black and two oriental.

\section{Blood Pressure Effects}

The placebo blood pressure (mean of three placebo periods) of the study population was $154 / 103(S D \pm 16 / 9) \mathrm{mm} \mathrm{Hg}$. Twenty of the patients had placebo diastolic pressure over 100 $\mathrm{mm}$ while six fell in the range $90-95 \mathrm{~mm}$. The 
(a)

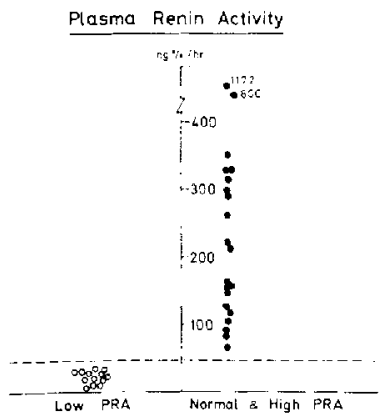

(b)

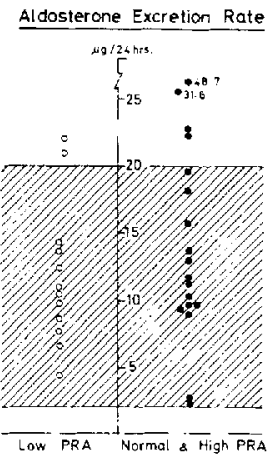

FIGURE 1. A. Distribution of plasma renin activity in 34 patients in this study. Three with low PRA and inadequate salt restriction have been excluded.

B. Urinary aldosterone excretion of patients illustrated in A.

three drug regimens, spironolactone $400 \mathrm{mg} /$ day, $200 \mathrm{mg} /$ day and chlorthalidone $100 \mathrm{mg} / \mathrm{day}$ had each significantly lowered $(P<0.001)$ systolic and diastolic pressure at the end of two weeks (Table 1). Chlorthalidone had elicited its full blood pressure effect by two weeks whereas with the spironolactone regimens further falls in pressure followed (Table 1).

The fall in pressure resulting from four weeks' treatment was not significantly different for the three regimens, being $\mathrm{S} 40024 / 13 \mathrm{~mm}, \mathrm{~S} 200$ $18 / 9 \mathrm{~mm}$ and $\mathrm{C} 10017 / 12 \mathrm{~mm}$ (Table 1). However, there was no correlation between the antihypertensive effect of the different drugs

and response to one did not necessarily indicate the likelihood of response to another. Normotension (diastolic $<90 \mathrm{~mm}$ ) was achieved in 21 patients with the high dose spironolactone, in 11 on moderate dose spironolactone and in 12 with chlorthalidone.

Initial diastolic pressure was linearly related to the fall in blood pressure resulting from S200 and $\mathrm{C} 100$. (S200, $r=0.4403, P<0.02, \mathrm{C} 100$, $r-0.3804, P<0.05)$. No such relation existed for $\mathrm{S} 400$, but subdivision of cases into three groups on the basis of placebo diastolic pressure $(<100,100-110,>110)$ revealed a greater effect of S400 $(P<0.05)$ on the highest in comparison with the lowest pressure group. The effect of all three drugs though was essentially similar in any one of these sub-groups.

\section{Plasma Renin Activity.}

Twelve of thirty-seven patients $(32 \%)$ had low $\left(<50 \mathrm{ng} \%\right.$ /hour) plasma renin activity $\left(\mathrm{PRA}^{1}\right)$ with satisfactory adherence to salt restriction (Table 2). The average twenty-four hour urinary sodium of this group was $127 \mathrm{meq}$ (range 88157). Three patients who had low plasma renin activity but excreted $>180 \mathrm{meq} \mathrm{Na}^{+} /$day were excluded from the renin analyses because such high sodium excretion may indicate an inadequate stimulus to renin secretion. At such high levels of urine sodium excretion it can become impossible to separate normal from low renin patients as is well illustrated in the nomograms constructed by Laragh's group ${ }^{7}$,

TABLE 1

Blood Pressures after Two and Four Weeks' Treatment.

\begin{tabular}{|c|c|c|c|}
\hline & $\begin{array}{l}\text { Spironolactone } 400 \mathrm{mg} \\
\text { (S400) }\end{array}$ & $\begin{array}{l}\text { Spironolactone } 200 \mathrm{mg} \\
\text { (S200) }\end{array}$ & $\begin{array}{l}\text { Chlorthalidone } 100 \mathrm{mg} \\
\text { (C100) }\end{array}$ \\
\hline Control (mm Hg \pm SEM) & $158 / 104 \pm 3 / 2$ & $155 / 104 \pm 3 / 2$ & $154 / 105 \pm 3 / 2$ \\
\hline $\begin{array}{l}2 \text { Weeks } \\
\triangle \mathrm{BP}\end{array}$ & $\begin{array}{c}139 / 96 \pm 4 / 2 \\
-19 / 8 \pm 3 / 2 \ddagger\end{array}$ & $\begin{array}{c}143 / 97 \pm 3 / 2 \\
-12 / 7 \pm 3 / 2 \ddagger\end{array}$ & $\begin{array}{l}139 / 94 \pm 3 / 2 \\
-15 / 11 \pm 2 / 2 \ddagger\end{array}$ \\
\hline $\begin{array}{l}4 \text { Weeks } \\
\triangle \mathrm{BP}\end{array}$ & $\begin{aligned} 134 / 92 & \pm 4 / 2 \\
-24 / 13 & \pm 3 / 2 *\end{aligned}$ & $\begin{array}{l}137 / 95 \pm 3 / 2 \\
-18 / 9 \pm 3 / 2+\end{array}$ & $\begin{array}{c}137 / 93 \pm 2 / 2 \\
\ldots 17 / 12 \pm 2 / 2 \ddagger\end{array}$ \\
\hline Change from 2-4 Weeks & $5 / 4 * \dagger$ & $6 / 0^{*}$ & $2 / 1 \mathrm{NS}$ \\
\hline
\end{tabular}

$\ddagger$ Denotes significance of $\mathrm{p}<0.001 \quad \dagger=\mathrm{p}<0.01 \quad *=\mathrm{p}<0.02$

The blood pressure levels achieved with the various drug regimens are not significantly different. 


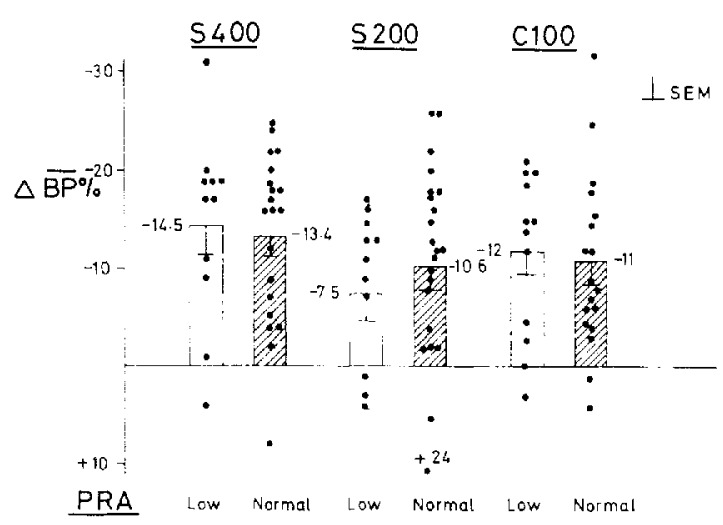

FIGURE 2. Change in mean blood pressure resulting from four weeks of treatment in patients grouped according to initial (low or normal) PRA levels.

which relate renin activity to urinary $\mathrm{Na}^{+}$ excretion. In one patient PRA was not measured. Figure 1A shows the distribution of plasma renin activity in the low and normal renin groups, while Figure 1B illustrates the 24 hour urinary aldosterone excretion in the same groups. The aldosterone excretion in normal and low renin groups was similar.

The decrease in pressure induced by each drug was highly significant $(P<0.001)$ (Fig. 2 ), irrespective of whether renin was low or normal. The antihypertensive effect of any of the three drugs failed to correlate with renin levels. The action of $\mathrm{S} 400$ in the low renin group was greater than that of S200 $(P<0.02)$ (Fig. 2). However, the effect of $S 200$ in the low renin sub-group was indistinguishable from that of C100.

No correlation was found between renin levels and initial plasma volume or changes in plasma volume resulting from treatment.

Plasma Renin Activity after Chlorthalidone $\left(P R A^{2}\right)$ and the ratio of $P R A^{2} / P R A^{1}$

Plasma renin activity estimation was repeated in seven patients with low PRA ${ }^{1}$ and in thirteen with normal PRA $^{1}$ after four weeks chlorthalidone $100 \mathrm{mg}$ /day. (Table 2, Fig. 3). PRA ${ }^{2}$ was invariably higher and while there was considerable overlap of $\mathrm{PRA}^{2}$ in the two subgroups, on the whole the initially normal PRA ${ }^{1}$ patients had higher PRA ${ }^{2}$ levels (1314 v. 439

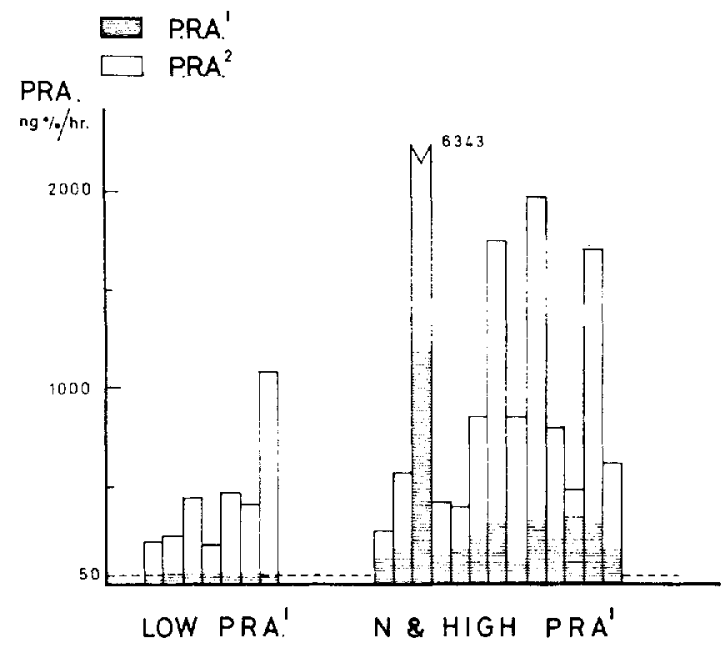

FIGURE 3. Baseline (PRA ${ }^{1}$ ) and chlorthalidone stimulated $\left(\right.$ PRA $^{2}$ ) plasma renin activity in groups suhdivided on basis of initial PRA level. Broken line indicates lower level of normal ( $50 \mathrm{ng} \% / \mathrm{hr}$ ) PRA ${ }^{1}$.

ng $\%$ /hour, $P<0 \cdot 02$ ). However, the percentage rise in the low renin patients was fourfold greater. Of the eight whose renin response to diuretic therapy was "most sensitive" (Table 2), all but one (No. 19) belonged to the initially low renin group.

\section{Urinary Aldosterone Excretion}

Urinary aldosterone and plasma renin activity were linearly related (no $-30, r=0.6049, P<$ $0 \cdot 001$ ), while both showed an inverse relationship to urinary sodium excretion (urinary aldo. $\mathrm{n}-30, r=-0.4801, P<0.01 ; \mathrm{PRA}^{1} \mathrm{n}=$ $35, r=-0.4125, P<0.05)$. The six patients with high $(>20 \mu \mathrm{g} / 24 \mathrm{hr})$ urinary aldosterone had a more marked diastolic pressure response to $\mathrm{S} 400$ than those where this variable was normal (24 v. $10 \mathrm{~mm}, P<0.01)$. A similar pattern was seen with $\mathrm{C} 100$, but not with $\mathrm{S} 200$. The aldosterone excretion rate bore no relationship to the untreated blood pressure.

\section{Plasma Volume and Weight}

Control plasma volume was $18 \cdot 2 \pm 0 \cdot 58 \mathrm{ml} / \mathrm{cm}$ height for males and $16 \cdot 1 \pm 0 \cdot 77$ for females $(P<0.05)$. The value, irrespective of sex was $17 \cdot 77 \pm 0.49 \mathrm{ml} / \mathrm{cm}$ ht (Table 3 ). This derivative correlates well with plasma volume expressed 
as a function of weight ( $\mathrm{n}=29, r=0.6779$, $P<0.001)$. The plasma volume $(\mathrm{ml} / \mathrm{cm})$ was found to be identical in males subdivided on the basis of control diastolic pressure (cut point $105 \mathrm{~mm} \mathrm{Hg}$ ).

Significant weight loss and decrease in plasma volume occurred with each four weeks' treatment (Table 3). However, weight loss bore no relationship to change in plasma volume or to blood pressure alterations. The drop in weight resulting from any of the three treatments was not influenced by initial plasma renin activity.

A greater decline in pressure was found in the low plasma volume group (upper and lower tertiles compared $P<0.01)$ on high dose spironolactone. There was no such difference in the effect of the two other regimens. There was a negative correlation between initial plasma volume and fall in mean blood pressure on S400 (n $-29, r=-0.545, P<0.01)$,

TABLE 2

Plasma Renin Levels in control period (PRA ${ }^{1}$ ), after 4 weeks Chlorthalidone $100 \mathrm{mg} /$ day $\left(\mathrm{PRA}^{2}\right)$ and ratio of $\mathbf{P R A}^{2} / \mathrm{PRA}^{1}$, as well as urinary sodium and aldosterone excretion at the time of PRA $^{1}$ sampling.

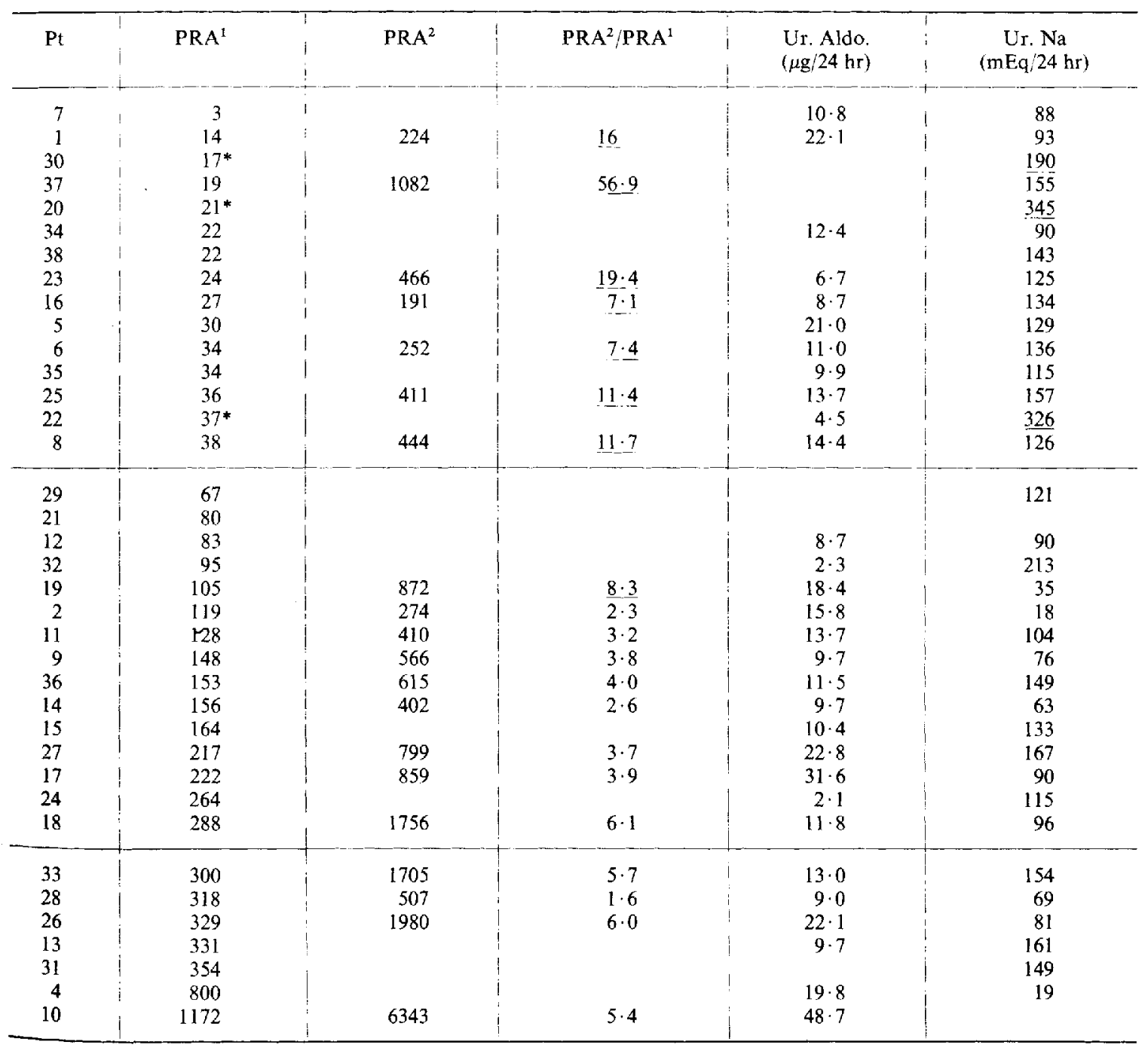

* Inadequate $\mathrm{Na}^{+}$restriction. 
TABLE 3

Plasma Volume (PV) and Weight (Wt.) ( \pm SEM): Changes $(\Delta)$ with four weeks treatment.

\begin{tabular}{|c|c|c|c|c|}
\hline & Control & $\mathrm{S} 400$ & $\mathrm{~S} 200$ & $\mathrm{C} 100$ \\
\hline Plasma Volume & & $\Delta \mathrm{PV}$ & $\Delta \mathrm{PV}$ & $\Delta \mathrm{PV}$ \\
\hline $\mathrm{ml} / \mathrm{cm} \mathrm{ht}$. & $17 \cdot 77 \pm 0 \cdot 49$ & $1 \cdot 53 \pm 0 \cdot 54^{*}$ & $-2 \cdot 05 \pm 0 \cdot 46 \ddagger$ & $-1.75 \pm 0.53 t$ \\
\hline $\mathrm{ml} / \mathrm{kg}$ wt. & $38 \cdot 42 \pm 1 \cdot 42$ & $3 \cdot 52 \pm 1 \cdot 22^{*}$ & $-4 \cdot 53+1 \cdot 02 \ddagger$ & $4 \cdot 11 \pm 1 \cdot 24 \dagger$ \\
\hline \multirow[t]{2}{*}{$\mathrm{ml}$} & $2995 \pm 104$ & $260 \pm 95^{*}$ & $-352 \pm 80 \cdot 2 \ddagger$ & $296 \pm 91 \cdot 3 \dagger$ \\
\hline & Control & $\Delta \mathrm{Wt}_{\mathrm{t}}$ & $\Delta \mathrm{Wt}$ & $\Delta \mathrm{Wt}$ \\
\hline Weight $\mathrm{kg}$ & $79 \cdot 51$ & $2 \cdot 0 \pm 0 \cdot 30_{+}^{+}$ & $-1 \cdot 2 \pm 0 \cdot 29_{+}^{+}$ & $-1 \cdot 9 \pm 0 \cdot 29+$ \\
\hline
\end{tabular}

whereas the pressure effect of the S200 and C100 regimens was independent of this variable. The decrease in plasma volume resulting from the three regimens was not correlated with their antihypertensive effect.

\section{Serum Potassium and Sodium}

The mean untreated serum potassium of the thirty-eight patients was $4.0 \pm 0.09 \mathrm{mEq} / l$. Four weeks' treatment with each diuretic caused the following changes:

Chlorthalidone $100 \mathrm{mg} /$ day, 4.1 to $3.0 \mathrm{mEq} / \mathrm{l}$ $(P<0.001)$.

Spironolactone $400 \mathrm{mg} /$ day, 4.0 to $4.3 \mathrm{mEq} / \mathrm{l}$ $(P<0.01)$.

Spironolactone $200 \mathrm{mg} /$ day, $4 \cdot 0$ to $4.2 \mathrm{mEq} / l$ (n.s.).

A small fall in serum sodium occurred with each treatment but this was not significant; e.g. chlorthalidone $100 \mathrm{mg}$ /day caused control level of $140 \pm 0.54$ to fall to $138 \pm 0.27 \mathrm{mEq} / l$.

\section{Discussion}

A similar antihypertensive effect has been noted in 38 uncomplicated essential hypertensives when given high ( $300-400 \mathrm{mg} /$ day) and moderate (200 mg/day) doses of spironolactone* for four weeks. The effect of chlorthalidone $100 \mathrm{mg} /$ day was comparable, although its action is indepen-

*Aldacione $A$ was first investigated in $196 \mathrm{1}^{13}$. Prior to that time the Aldactone available was roughly one fourth as potent. The name Aldactone $A$ was changed to Aldactone in $1965-66$, so that the currently available Aldactone is $4 \gamma^{\prime}$ more
potent than the preparation of the same name available in the late fifties and potent than
early sixties. dent of mineralocorticoid antagonism. Subdivision of patients on the basis of initial plasma renin activity $\left(\mathrm{PRA}^{1}\right)$ or diuretic stimulated renin $\left(\mathrm{PRA}^{2}\right)$ failed to indicate a pattern of blood pressure response which could be related to these parameters on any of the three treatments. The low renin sub-group did not show a greater response to high dose spironolactone and chlorthalidone was as effective.

The separation of a portion of essential hypertensives into a low renin category may be artificial and it's quite possible that we are merely looking at the lower end of a normal distribution. Thus, a clear distinction of response to treatments would not necessarily be expected on the basis of renin levels and even if such a distinction were found it would not have to imply the existence of a distinct entity of "low renin essential hypertension". Nor indeed would it favour the postulate of excessive mineralocorticoid activity unless the response was confined to a specific mineralocorticoid antagonist.

The similarity of response of the low renin group to spironolactone and chlorthalidone does not contradict the postulate of excessive mineralocorticoid being responsible for the renin suppression. It is possible that mineralocorticoid inhibition, as with spironolactone or the facilitation of sodium excretion with chlorthalidone can have similar effects on blood pressure and plasma volume.

The observed lack of correlation between the antihypertensive effects of S400 and C100 is 
hard to explain as their net BP effect on the group as a whole is similar, and presumably they have a common final path of action through salt and water excretion. The effect of $\mathrm{S} 200$ in the low renin group is significantly less than that of $S 400$, but rather than illustrating a selective action of $\mathrm{S} 400$ in low renin hypertension, the result could indicate a relative lack of response to $\mathbf{S} 200$. The high dose and duration of spironolactone treatment used in this study was comparable to other regimens in the recent literature ${ }^{1 \cdot 4,6}$.

The results of Jose, Crout and Kaplan ${ }^{6}$ agree with the finding in this paper in showing a uniform antihypertensive effect from spironolactone in normal and low renin sub-groups. While their doses have been criticised as inadequate to achieve total blockade in situations of increased mineralocorticoid secretion, Gwinup and Steinberg ${ }^{10}$ have noted marked BP responses to the same dose of spironolactone in proven mineralocorticoid hypertension. The more recent studies of Vaughan et $a l^{7}$ have also found a lack of selective spironolactone action in low renin hypertension, with the demonstration that chlorthalidone has a similar antihypertensive effect. The dose of spironolactone in that study was variable $(50-400 \mathrm{mg})$ with the most common dose being $200 \mathrm{mg}$ /day or less, administered as an open label preparation. Nearly $40 \%$ of low renin hypertensives in the study of Vaughan et $a l^{7}$ were aged above 60 years, whereas only three out of 28 of the normal renin groups exceeded this age. The work of Adlin et al. ${ }^{4}$ indicates that the "low" renin sub-group may also be more responsive to hydrochlorothiazide. We would have some reservations about the interpretation of these results, as a "low" renin group has been created by pooling results of truly low and "low normal" renin patients. Comparison of their truly low renin patients with the rest still shows high dose spironalactone and hydrochlorothiazide to have comparable effects, but the low renin sub-group is no longer distinguishable as more responsive.

Twelve of thirty-seven patients $(32 \%)$ in this study were found to have low plasma renin activity, and this figure is in agreement with most other series ${ }^{1,2,6,14}$. However, analysis of renin after four weeks of $\mathrm{C} 100$ in the low renin patients showed that the renin-angiotensin axis was in one respect more responsive, as the percentage rise in renin was found to be greater than that of the normal PRA group (Table 2). These findings raise the important question of a standardised renin stimulus ${ }^{15-19}$ before essential hypertensives are labelled as "low renin hypertensives". While Carey's group ${ }^{3}$ employed frusemide in their preparation, others ${ }^{15}$ have shown that added salt restriction $\left(10 \mathrm{mEqNa}^{+} /\right.$Day) further reduced by $15 \%$ the number falling in the low renin category. Crane and colleagues ${ }^{2}$ demonstrated that with repeat testing the number in the low renin sub-category progressively declines.

Several series ${ }^{1-3}$, by showing a marked dependence of the antihypertensive properties of spironolactone on renin levels, are at variance with this study. However, the composition of our low renin group, with five white males, four black males, two black females and one white female is somewhat different to that of Spark and Melby ${ }^{1}$ who in a group of eight low renin hypertensives had seven females of whom six gave a past history of toxaemia of pregnancy. While our patients have clearly milder hypertension than those in other studies ${ }^{13}$, the pressures are comparable to those of Wood's et al. ${ }^{5}$. Besides, the BP effect of $\$ 400$ observed by Spark and Melby ${ }^{1}$ and Carey et al. ${ }^{3}$ is considerably in excess of that seen when mineralocorticoid blockade was achieved by aminogultethimide ${ }^{5}$. This raises the possibility of an antihypertensive effect from S400 in addition to that resulting from mineralocorticoid antagonism. Further, the effect of S100 maintenance on subsequent BP levels is not uniform ${ }^{1,3}$.

Baseline plasma volume in this series corresponds closely with Tarazi et al's ${ }^{20}$ figures in essential hypertensives and the significantly lowered plasma volume at four weeks is in keeping with a slow spironolactone effect. The finding that the volume effect of chlorthalidone in the group as a whole is similar to that of spironolactone, could indicate a subset of essential hypertensives which is volume sensitive, responding non-specifically to any alteration in plasma volume. The lack of correlation between the observed plasma volume effects of 
chlorthalidone and spironolactone is not incompatible with the postulate of a volume sensitive group, but it does suggest that different individuals may respond to the two groups of diuretics. It is hard to explain the preferential action of high dose spironolactone ( $\mathrm{S400)}$ on the BP of the low plasma volume group in this study, but it is not the pattern to be expected if S400 were acting on excess of an unidentified mineralocorticoid ${ }^{21}$. None of the three regimens showed a correlation between decrease in plasma volume and change in blood pressure. The significant weight loss with each treatment at four weeks bore no relation to alterations either in plasma volume or blood pressure and this may indicate variation in individual sensitivity of different patients to diuretics. Further studies on the changes in various body fluid compartments may offer insights into these problems.

In the light of our findings that $S 400, S 200$ and $\mathrm{C} 100$ have equivalent antihypertensive effects on groups of uncomplicated essential hypertensives subdivided on the basis of plasma renin activity, it would be hard to recommend routine screening of essential hypertensives for plasma renin activity for possible therapeutic benefit. The work of Adlin et $a .^{4}$ and Vaughan et al. $^{7}$, while showing a heightened BP response to spironolactone in low renin hypertension agrees with our findings in demonstrating a similar effect from thiazide type diuretics.

In this study, the dynamic response of the renin-angiotensin axis and plasma volume to diuretics appears no less in low renin hypertension than in normal renin essential hypertensives. We have also confirmed that spironolactone does not necessarily have a "specific" BP effect in low renin hypertensives as its antihypertensive action in high doses in low and normal renin sub-groups resembled that of chlorthalidone. This finding is supported by recent evidence on the similarity of effect of spironolactone and amiloride on the blood pressure and metabolic parameters of cases of aldosterone secreting adenomas ${ }^{22}$.

\section{Acknowledgements}

We are indebted and grateful to Professor Sibley W. Hoobler, Stevo Julius M.D. and J. Carlos Romero M.D. for valuable guidance. Searle Laboratories gave valued support. We sineerely thank Miss Charlotte Hartyánszky for the illustrations and Miss Linda Atwill for the typing.

\section{References}

1. SPARK, R. F. and MelBy, J. C. (1971): Hypertension and low plasma renin activity. Presumptive evidence for mineralocorticoid excess, Ann. intern. Med.. 75, 831

2. CRANT, M. G., HARRIS, J, J, and JoHNS, V. J. (1972): Hyporeninemic hypertension, Amer. J. Med., 52, 457.

3. Carfy, R. M., Dolglas, J. G., Schweikert, J. R. and Liddie, G. W. (1972): The syndrome of essential hypertension and suppressed plasma renin activity, Arch. intern. Med.. 130. 849.

4. Adilin, E. V., Marks, A. D. and Channick, B. J. (1972): Spironolactone and hydrochlorothiazide in essential hypertension, Arch imtern. Med., 130, 855 .

5. Woods, J. W., Liddle, G. W., Stant, E. G., Michelakis, A. M. and BrILl., A. B. (1969): Effect of an adrenal inhibitor in hypertensive patients with suppressed renin, Arch. intern. Med., 120, 366 .

6. JosE. A., Crout, J. R. and KAPLAN, N. M. (1970): Suppressed plasma

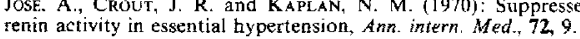

7. Valghan, E. D. Jr., Laragh. J. H., Gayras, I., Blihi.f., F. R., Gavras, H., BRLNNER, H. R. and BAER, L. (1973): Volume factors in low and normal renin essential hypertension, Amer. $J$. Cardiol, $32,523$.

8. Grim, C. E. and Phters, T. J. (1971): Low renin hypertension: A state of inappropriate secretion of aldosterone? Circulation 44, (Suppl. II), 172.

9. Kuchel, O.. Cucie, J. L., Barheai, A., Hamet, P., Boucher, R., Nowa C.YNSKI, W. and GENEST, J. (1970): Low renin hypertension and betaadrenergic hyperreactivity, two extreme poles of "essential" hypertension,
Circulation \$2, (Suppl. III), 70.

10. Gwinup. G. and STEINeERG, T. (1967): Differential response to thiazide and spironolactone in primary aldosteronism, Arch. intern. Med., 120,436.

Julius, S., PAscual, A. V., Reiley, K. and Lonison, R. (1971): AbnormaliJuluUS, S., PASCUAL, A. V., REILEY, K. and LONiON, R. (1971): Abnormali-
ties of plasma volume in borderline hypertension, Arch. iniern. Med., 127, ties of 116 .

12. Haber, E., Koerner, T., Page, L. B. Kliman, B. and Purvode, A. (1969): Application of a radioimmunoassay for angiotensin $I$ to the physiologic measurements of plasma renin activity in normal human subjects, J. clin. Endocr., 29, 1349.

13. Beack, SuSANne J. (1972): Personal communication, Searle Labs., Chicago, Ill

14. Küchel, O., Fishman, L. M., Liddee, G. W. and Michelakis, A. M. (1967): Effect of diazoxide on plasma renin activity in hypertensive patients, Ann. intern. Med., 67, 791.

15. ChavNick, B. J., AvLin, E. V. and Marks, A. D. (1969): Suppressed plasma renin activity in hypertension, Arch. intern. Med., 123, 131

16. HeLmer, O M. (1969): Renin activity in blood from patients with hypertension, Canad. med. Ass. J, 90, 221.

17. Creditor, M. C. and Loschky, U. K. (1967): Plasma renin activity in hypertension, Amer. J. Med., 43, 371.

18. Wfinbrrger, M. H., Dowdy, A. J., Nokes, G. W and Leltscher, J. A (1968): Plasma renin activity and aldosterone secretion in hypertensive patients during high and low sodium intake and administration of diuretic. J. clin. Endocr., 28, 359.

19. Fishman, L. M., KüChel, O, Liddlf, G. W., MichelaKis, A. M., Gordon, R. D. and CHICK, W. T, (1968): Incidence of primary aldosteronism in uncomplicated essential hypertension: A prospective study with elevate aldosterone secretion and suppressed plasm
nostic criteria, J. Amer. med. Ass., 205, 497 .

20. Tarazi, R. C., Frohlich, E. D. and Dustan, H. P. (1968): Plasma volume in men with essential hypertension, New. Engl. J. Med., 278, 762.

21. Hunyor, S. N., ZwhifLtr, A. J. and Hansson, L. (1973): Effect of spironolactone and chlorthalidone in essential hypertension: relation to plasma renin activity and plasma volume, Circulation 48, (Suppl. IV), 83 .

22. Bervers, D. G., Brown, J. J., Ferris, J. B., Fraser, R., Lever, A. F. and RonerTSON, J. I. S. (1973): The use of spironolactone in the diagnosis and the treatment of hypertension associated with mineralocorticoid excess Amer. Heart J., 86, 404 . 